\title{
INSTITUCIONALIZACIÓN DEL SER EN LOS CORTOMETRAJES LA FÁBRICA Y NO BINARIO
}

Laura Marcela Miranda Bello*

DOI: https://doi.org/10.33571/revistaluciernaga.v11n22a3

\section{Resumen}

El artículo presenta la reflexión producto del análisis de los cortometrajes La Fábrica y No Binario. Se encontró que ambos cortometrajes hacen una particular construcción simbólica de la institucionalización del ser desde lo social y lo familiar así como de la perspectiva de género mediante el cuerpo como discurso social y la identidad.

Palabras clave: género; instituciones sociales; cuerpo; roles; identidad; narrativa audiovisual; ACDM.

Recibido. Febrero 18, $2019 \quad$ Aceptado. Abril 23, 2019

* Magister en Comunicación - Educación en la línea de investigación: Medios interactivos. Universidad Distrital Francisco José de Caldas. Orcid: https://orcid.org/0000-0002-5233-0971; e-mail: lamirabe1501@Perspectiva de génerogmail.com 
ESTABLISHMENT OF THE SELF

IN THE SHORT FILMS THE FACTORY AND NOT BINARY

Laura Marcela Miranda Bello*

DOI: https://doi.org/10.33571/revistaluciernaga.v11n22a3

\section{Abstract}

The article presents the results of the analysis the short films The Factory and NonBinary. It was found that both short films have a particular symbolic construction of the establishment of the self from the social and the family view, as well as from the gender perspective through the body as social discourse and identity.

Key words: gender; social institutions; body; roles; identity; narratives; audiovisuals; ACDM.

Received. February 18, $2019 \quad$ Accepted. April 23, 2019 


\section{INSTITUCIONALIZAÇÃO DO SER} NAS CURTAS METRÁGENS A FÁBRICA E NÃO BINÁRIO

Laura Marcela Miranda Bello*

DOI: https://doi.org/10.33571/revistaluciernaga.v11n22a3

\section{Resumo}

O artigo apresenta os resultados da análise aplicado aos curtas-metragens The Factory and Non-Binary. Descobriu-se que ambos os curtas-metragens fazem uma construção simbólica particular da institucionalização do ser a partir da perspectiva social e familiar, bem como da perspectiva de gênero através do corpo como discurso social e identidade.

Palavras chave: gênero; instituições sociais; corpo; papéis; identidade; narrativas; audiovisuais; ACDM.

Recebido. Fevereiro 18, $2019 \quad$ Aceitado. Abril 23, 2019

* Mestrado em Comunicação - Educação na linha de pesquisa: Mídia interativa. Universidade Distrital Francisco José de Caldas. Orcid: https://orcid.org/0000-0002-5233-0971; e-mail: lamirabe1501@gmail.com 


\section{Introducción}

Los procesos sociales e históricos juegan un rol importante en la constitución del individuo. En este sentido comprender la forma en que cada uno de los sujetos elabora sus sistemas ideológicos y de convicciones se considera imperioso, ya que a través de ello se logra develar la intervención de las instituciones sociales para su consolidación en el pensamiento tanto individual como colectivo. Esto implica que dichos sistemas son establecidos bajo parámetros de carácter social, cultural e histórico, creando así discursos que estipulan una serie de fundamentos axiológicos y ontológicos que determinan la identidad y pertenencia de los sujetos a grupos sociales particulares.

El concepto de género ha sido motivo de reflexión en diversos grupos sociales especialmente en torno a la inclusión y exclusión. En general esto se ha hecho desde una perspectiva tradicional y patriarcal. Su definición se ha visto regulada por los roles asignados a cada género sin embargo nuevas posturas han permitido cambios en las prácticas sociales en relación con el género.

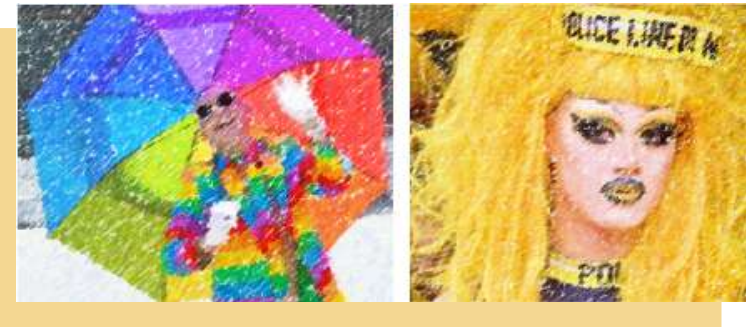

Simone de Beauvoir (1962) en su trabajo El Segundo sexo, plantea su concepción del ser hombre o mejer, señalando que estos son constructos consensuados, tradicionales y biológicos, es decir, que son producto de la representación significativa de una comunidad. Para esta filósofa "no se nace sino que se hace mujer". Beauvoir marca una época coyuntural para el surgimiento y posterior consolidación del movimiento feminista a mediados de la década de los setenta, dando así paso a lo que hoy se conoce como estudios de género.

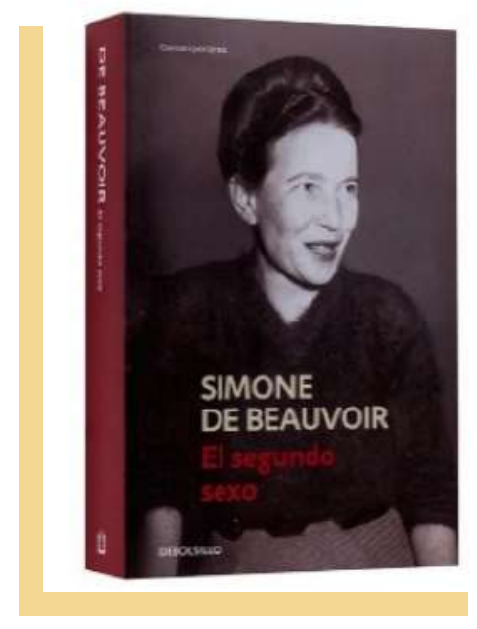

Para Lamas (1986) "estos papeles, que marcan la diferente participación de los hombres y las mujeres en las instituciones sociales, económicas, políticas y religiosas, incluyen las actitudes, valores y expectativas que una sociedad dada conceptualiza como femeninos o masculinos" (p. 98). Butler (2001) en el primer capítulo de su libro Género en disputa, señala que "el género se construye culturalmente: por esa razón, el género no es el resultado causal del sexo ni tampoco es tan aparentemente rígido como el sexo" (p. 54). Por consiguiente, el género es un constructo cultural que trasciende los aspectos meramente físicos y biológicos.

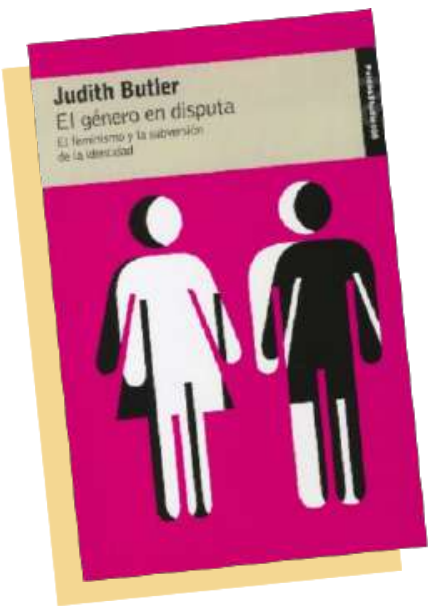

En este cambio de paradigmas sociales y culturales, genera interés abordar la concepción de género desde la perspectiva de los jóvenes, quienes para Reguillo (2000) en tanto agentes sociales cuentan con "competencias para referirse 
en actitud objetivante a las entidades del mundo" (p.36) es decir que como sujetos de discurso son capaces de apropiarse (y movilizar) los objetos sociales, simbólicos y materiales de una sociedad.

En el actual contexto tecno mediado construcciones emergentes sobre la sociedad han adquirido nuevas formas de producción y distribución, esto implica la reflexión acerca de los nuevos sentidos sociales y culturales debido a la influencia de las imágenes, el sonido y nuevas propuestas narrativas, como formas alternativas de recrear el mundo.

\section{Metodología}

Para cumplir el objetivo principal de la investigación, el cual fue identificar la construcción simbólica de la institucionalización del ser, se abordaron los cortometrajes La Fábrica y No Binario, producciones realizadas por estudiantes adscritos al programa de cine y televisión de una universidad privada de la ciudad de Bogotá. Estas producciones audiovisuales fueron realizadas bajo los parámetros de cortometraje, según Lasierra y Bonaut, (2016), el cortometraje es:

"una narrativa sin estructuras y convenciones rígidas, abierta a la experimentación y al juego, que se adapta a las necesidades históricas y temáticas, y que es directa y concisa" (p.423).

Para la recolección y análisis se utilizó la metodología denominada Análisis Crítico del Discurso Multimodal (ACDM), planteado por Kress y Van Leeuwen (2001) quienes consideran que en todos los procesos comunicativos intervienen elementos enriquecedores para el significado de un mensaje.

Desde la perspectiva de esta metodología las producciones audiovisuales utilizan elementos semióticos como las imágenes, colores, sonidos, etc., que a su vez son sistemas gestores de significado. Para Kress and Van Leeuwen, esta metodología se basa en el desarrollo de cuatro estratos analíticos los cuales responden a la forma en la cual se configura y se expresa el contenido. Estos son: discurso, diseño, producción y distribución.

Discurso. Identificación de los discursos de tipo social, es decir los conocimientos que se construyen mediante consensos sociales. Para el caso se implementó una matriz de análisis, se cotejó el contenido de las historias de los cortometrajes, teniendo en cuenta la manera en que los hechos fueron narrados, los personajes y su actuación así como los lugares en que las historias se llevaron a cabo, para eventualmente identificar los discursos más recurrentes entre las dos piezas. Esta primera fase, se realizó bajo los constructos teóricos que soportaron la investigación.

Diseño. Consiste en identificar el mensaje que los productores de los cortometrajes desean trasmitir, y los recursos semióticos empleados para la representación de dicho mensaje. Para el caso específico de este análisis los recursos que se emplearon corresponden a los de tipo visual, textual y lingüístico.

Producción. En este estrato se interpretan los discursos identificados, el manejo y uso de técnicas descritas en el diseño, los cuales se materializan en los cortometrajes.

Finalmente, se encuentra el estrato de distribución el cual corresponde a la forma en el que el mensaje planteado en los cortometrajes es difundido. Los productores contaron con plena libertad creativa para la presentación de sus contenidos así como para decidir el canal de difusión de sus productos. Ellos compartieron estos cortometrajes en Youtube. En este estrato, se debe comprender que el contenido expresado en los discursos da cuenta de las construcciones sociales, históricas y culturales que estos jóvenes han estructurado sobre género dentro de su entorno particular, cuya repercusión en el ámbito social pueden proporcionar nuevas interpretaciones y la exposición de la cosmovisión de un grupo de jóvenes en particular. 


\section{Resultados}

De la triangulación de datos en la matriz de análisis, surgieron dos categorías que a su vez se caracterizan cada una, desde dos dimensiones. La primera Institucionalización del ser: Desde lo social y lo familiar, y la segunda Perspectiva de género: desde el cuerpo como discurso social y desde la identidad dentro de la generalidad.

\section{- Perspectiva de género}

En el cortometraje La Fábrica, se lleva a cabo un proceso de selección de cada uno de los individuos a partir del símbolo de hombre y mujer el cual tienen estampado en su pecho. Quienes no poseen dichos símbolos, son rechazados y marcados con colores llamativos como estrategia narrativa que acentúa este hecho. Sus cuerpos denotan una naturaleza indefinida, asexuada.

Es decir, los componentes físicos y biológicos no se presentan de una manera explícita, haciendo que la distinción entre los individuos sea dada por una consonancia entre el cuerpo (como primera evidencia de la diferencia humana) y las diferentes construcciones hechas socioculturalmente.

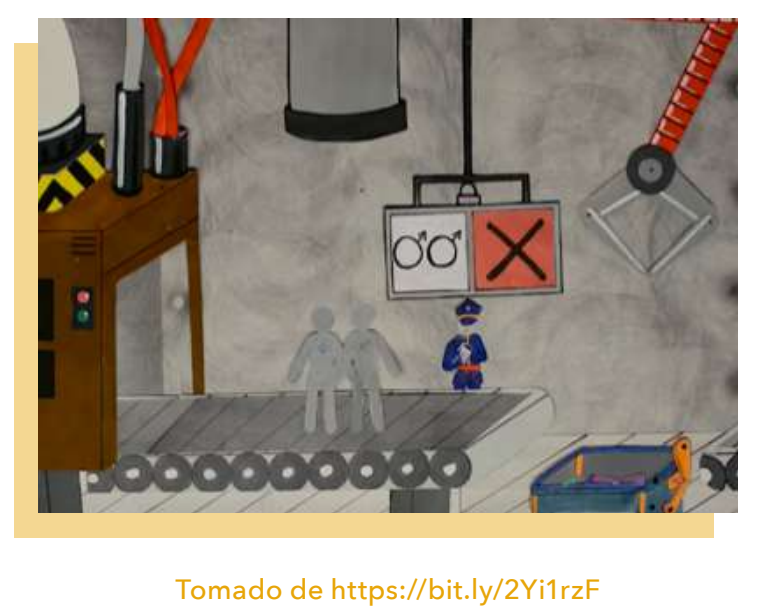

Como sabemos a lo largo de la historia se han presentado contenciones vinculadas al cuerpo como diferenciación entre hombres y mujeres que rebasan los aspectos meramente biológicos. Estas diferencias derivaron una situación inequitativa para las mujeres tanto en las esferas políticas, económicas como culturales, ya que tanto las características físicas como intelectuales tanto de hombres como de mujeres se determinaron a partir del aspecto corpóreo de cada quien, como expresa Lamas (2002):

"la cultura es un resultado, pero también es una mediación. Los seres humanos nos vemos enfrentados a un hecho básico, que es idéntico en todas las sociedades: la diferencia corporal entre mujeres y hombres, específicamente la relativa a los genitales. La cultura es resultado de la forma como interpretamos esta diferencia, de cómo la simbolizamos, de cómo elaboramos la angustia o el miedo que nos genera; pero también la cultura es una mediación: un filtro a través del cual percibimos la vida" (p. 5)

A lo largo de la historia se han presentado contenciones vinculadas al cuerpo como diferenciación entre hombres y mujeres que rebasan los aspectos meramente biológicos. Estas diferencias derivaron una situación inequitativa para las mujeres tanto en las esferas políticas, económicas como culturales, ya que tanto las características físicas como intelectuales tanto de hombres como de mujeres se determinaron a partir del aspecto corpóreo de cada quien.

El sistema social confiere tanto a hombres como mujeres una serie de códigos comportamentales, así como un determinado desempeño en diversas actividades cotidianas que van articulados con la fisonomía corporal de cada uno, llenando así las expectativas sociales y culturales que se generan en cada uno por sus características innatas. Dichas expectativas y códigos consensuados de conducta en hombres y mujeres se manifiestan en No Binario a través de una escena en que una mujer lleva un niño de la mano, esta como figura representativa de uno de los roles que debe desempeñar cada mujer en el entramado social como guía y protectora del hogar, es quien se hace cargo de la formación de los hijos.

En esta misma línea se encuentra el niño quien usa un uniforme de fútbol cuyo significado reafirma las conductas y actitudes socialmente establecidas que se le confieren al hombre a través de una actividad o deporte. 


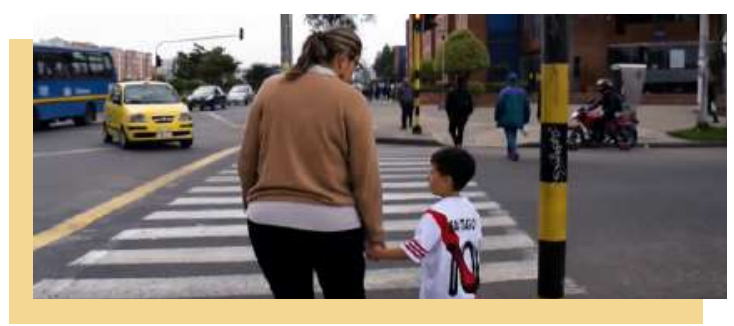

Tomado de: https://bit.ly/3cl4kh1

Otra perspectiva del cuerpo como una representación de discursos sociales y culturales se visualiza a través de la técnica de producción de voz en off cuya característica principal es la retrasmisión de la voz del personaje, pero este no se logra captar visualmente. No Binario es narrado con la voz de una mujer, dando la impresión que la historia gira en torno a ella, esto se complementa con el uso de imágenes en primer plano que capturan rasgos femeninos del rostro como los ojos y las cejas. Sin embargo, solo hasta el final de la historia la identidad del personaje es revelada. Al entrar a un baño, su reflejo en el espejo es de un hombre y finaliza su monólogo diciendo "Me he dado cuenta que simplemente soy humano".

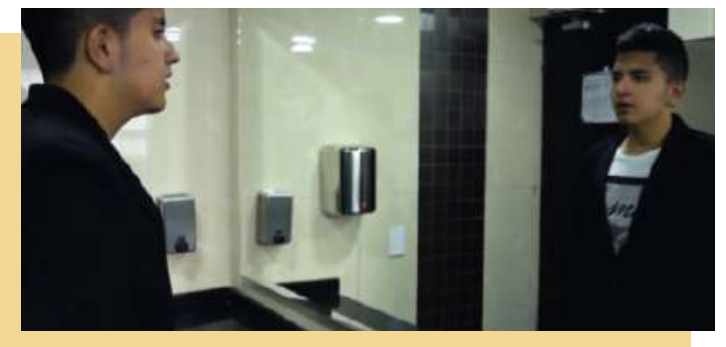

Tomado de: https://bit.ly/2XXs7FL
De esta manera se hace evidente la diferenciación sobre el concepto que la sociedad posee sobre él (hombre) y la apropiación que el personaje posee sobre sí mismo (mujer), en donde su autoconcepto va más allá de una diferenciación física de su sexo. Estas características dan paso a la emergencia de construcciones divergentes, difusas, que no encajan en lo "moral y socialmente" establecido, resaltando así la fragilidad de un sistema y su posibilidad de reconfiguración. Se considera el género como un concepto subversivo, en el cual las personas tienen la capacidad de replantear cada una de las normas sociales que estipulan la manera en que se debe ser y actuar, dando como resultado el establecimiento de sus propios límites en la constitución de su propio yo (Butler, 2006)

El acto de ver su reflejo en el espejo, el personaje de No Binario revela la dualidad en la que se halla inmerso (entendida esta como una dicotomía entre cuerpo e identidad), muestra como la construcción de la identidad no solo se regula por parámetros socioculturales sino por la capacidad que posee el sujeto para reconfigurar dichos parámetros, que le son asignados desde su nacimiento, permitiendo así la sublevación del ser. En este punto, se considera la que identidad de género trasciende la corporeidad.

\section{- Institucionalización del ser}

Uno de los discursos recurrentes en La Fábrica y No Binario, es la influencia que infringen las instituciones sociales y organizaciones aceptadas colectivamente en la formación física, intelectual y emocional de cada ser humano.

La historia del cortometraje La Fábrica se desarrolla en un ambiente melancólico y hosco de tipo industrial, cuya función se limita a la creación de hombres y mujeres que siguen conformes la reglamentación establecida de su estructura social. Todo aquel que no cumpla dichas estipulaciones es desechado en un contenedor de basura para luego ser maltratado. 

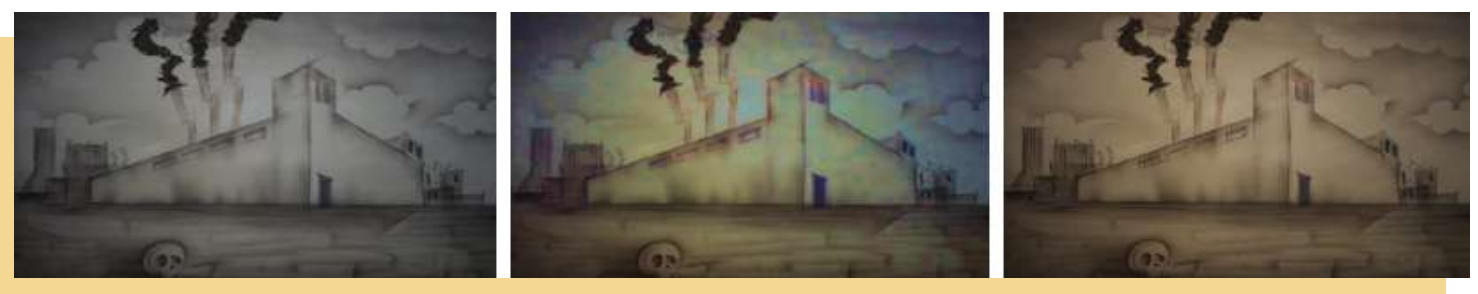

Tomado de https://www.youtube.com/watch?v=Jkj4UZEf2MA\&t=218s

Como primera reflexión surge el proceso de deshumanización de los seres humanos, cuyo sometimiento se ha visto ejecutado por los intereses de las estructuras sociales y los discursos hegemónicos que establecen un orden social y cultural. Dicho proceso se ve reflejado a través de estrategias narrativas como el diseño de personajes unidimensionales y sin rastro de rasgos humanos. De igual manera, el empleo de colores monocromáticos como el gris tanto en los personajes como en las escenas, recrean un ambiente sombrío, homogeneidad y actitud de subordinación frente a esta institución, que refuerza la idea Foucaultiana que menciona el carácter moldeador que posee la fábrica como dispositivo de control (Foucault, 1990)

Así como el color gris cuenta con gran relevancia en la producción de significado, el color blanco y negro no son la excepción. El cabezote del cortometraje inicia con el título La Fábrica con letras en color blanco, sobre un espacio negro. De acuerdo con Wong (1992), a este título se le considera un espacio "vacío", mientras que el fondo negro se le llama espacio "ocupado", lo que ofrece una connotación positiva 0 negativa dependiendo de la forma en que el espectador la intérprete.

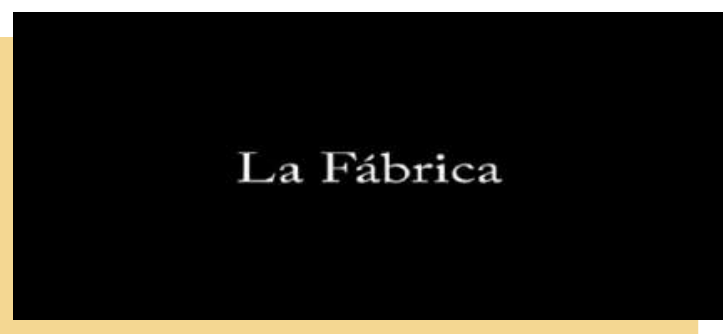

Tomado de https://bit.ly/2Y1dNfe

En el cortometraje, el negro que ocupa todo el espacio en el cabezote captura la mayor parte del campo visual de la audiencia, evocando sentimientos negativos. De esta forma, desde la teoría del color, el negro representa la ausencia de color, de luz y vida (Heller, 2004) Esto se contrasta con el título cuya aparición es bastante reducida, a pesar de su significado relacionado a la luz y la pureza.

Las instituciones sociales para lograr el cumplimiento a cabalidad de sus exigencias poseen mecanismos y técnicas de vigilancia, las cuales facilitan la formación de las personas, así como el encauce de su conducta. Ello se efectúa mediante la observación, la implantación de dictámenes, la modelación de fundamentos sociales y culturales.

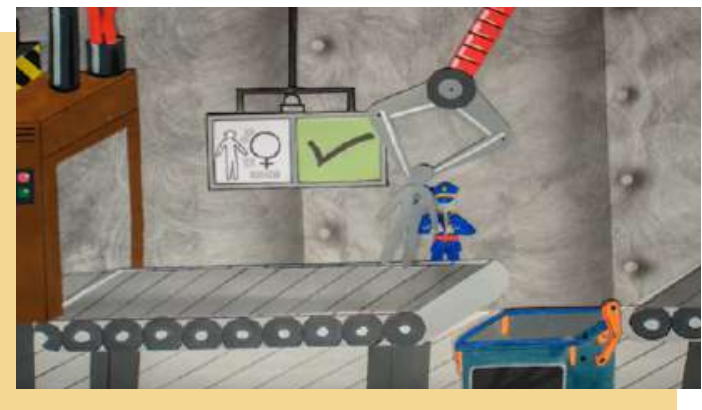

Tomado de https://bit.ly/2VRUPVY

Cabe aclarar que la imposición de ideologías y discursos se hace por parte de los diferentes organismos de poder presentes en el panorama social como los partidos políticos, tradiciones y creencias religiosas, programas de televisión, la industria del entretenimiento y la moda, los grupos en redes sociales, etc. Estos ejercen su poder de manera discreta, cada una de las actividades cotidianas de los seres humanos no escapan de la naturaleza ubicua que poseen estos dispositivos de control, cuyo fin es manipular, dominar y corregir, obteniendo así seres humanos dóciles. 
La Fábrica como dispositivo se considera esquemade control capazdehomogeneizar condiciones y rasgos. La familia configura los seres humanos; provista de un sistema de normas que guía la interacción entre sus miembros dentro de la sociedad.

En el cortometraje No Binario, se devela la influencia ejercida por el grupo familiar en la manifestación de creencias, ideologías, así como en la forma en que cada persona se debe relacionar con el mundo exterior. Su personaje reflexiona sobre su sentir con el mundo y sí mismo, centrando su mirada en una familia, acción que acompaña diciendo: ¿Por qué dejar que alguien más decida por mí? La familia determina los patrones axiológicos y comportamentales de cada ser humano.

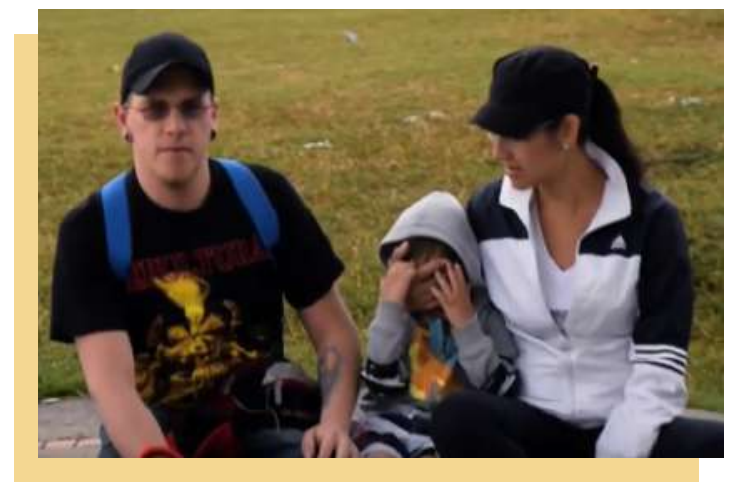

Tomado de: https://bit.ly/2Sj8eWb
Por otra parte, el tono de voz y la actitud meditabunda del personaje de este cortometraje expresa su inconformidad frente al modelo tradicionalista de la familia en la que por largo tiempo la sociedad ha cimentado sus convicciones y construcciones sobre el mundo, e intervenido en el libre desarrollo de los seres humanos.

Tal como lo expresan Pérez Lo Presti y Reinoza (2011) "Desde su origen, la familia tiene varias funciones que podríamos llamar universales, tales como: reproducción, protección, la posibilidad de socializar, control social, determinación del estatus para el niño y canalización de afectos, entre otras" (p.629).

Como estrategia narrativa para la recreación de la reiteración de este constructo social, se empleó el plano medio, en No Binario, se captura la atención de la figura de la familia , aislándola del entorno circundante. Narrativamente, este plano permite establecer una relación más íntima entre los personajes. El hombre, la mujer $y$ el niño juntos sugieren en el espectador el concepto tradicionalista de familia y las implicaciones que esta imagen posee en el imaginario social.

\section{Conclusión}

Teniendo en cuenta el objetivo general, cabe resaltar en primera instancia el espíritu crítico y emancipador que se imprimieron a cada uno de los cortometrajes. Los jóvenes realizadores, en sus propuestas audiovisuales de naturaleza creativa exponen tejidos socio-históricos que han intervenido en la constitución holística del sujeto. Bajo estas condiciones, se logra visualizar el influjo que las instituciones ejercen en el entramado ideológico de la sociedad consolidado esto en la figura de la fábrica y la familia.

A través de la figura de la fábrica, se pretende hacer una alusión a cada uno de los organismos de control que se encuentran

en el panorama actual, cuyo objetivo es la implementación de normativizaciones en las cuales los individuos de una comunidad deben ceñir sus valores, creencias y actuaciones. De esta forma, los procesos de identidad de los individuos se supeditan a los discursos de poder como métodos eficaces de homogeneización y modelación de todo un colectivo. Sin embargo, en todo sistema de poder y control, se generan prácticas de resistencia u oposición, proclamados como mecanismos para lograr la emancipación, interpretaciones divergentes sobre el mundo.

El cortometraje La Fábrica expone la fragilidad y a la vez ruptura de un sistema tradicionalista, en el cual se lleva a cabo 
una taxonomía sobre los hombres y mujeres a partir de las construcciones consuetudinarias. El empleo de los símbolos de masculino y femenino en los personajes se considera una prueba evidente de dichas convenciones sociales, Sin embargo, las formas unidimensionales $y$ asexuadas de los personajes al igual que el empleo de colores vivos en sus cuerpos durante el proceso de selección visibilizan la transgresión de la categorización binaria (hombre y mujer), dejando entrever la subversión del género, llevado a cabo por los actos performativos que deconstruyen las prácticas sociales.

Seres humanos inmersos en la monotonía del gris evocan su adaptación al sistema que regula su existencia y esencia, pero la intervención de colores como azul, verde, rosado, etc., funcionan como respuesta a los sistemas de represión y dominación, facilitando así la aparición de nuevas propuestas de la construcción del ser.

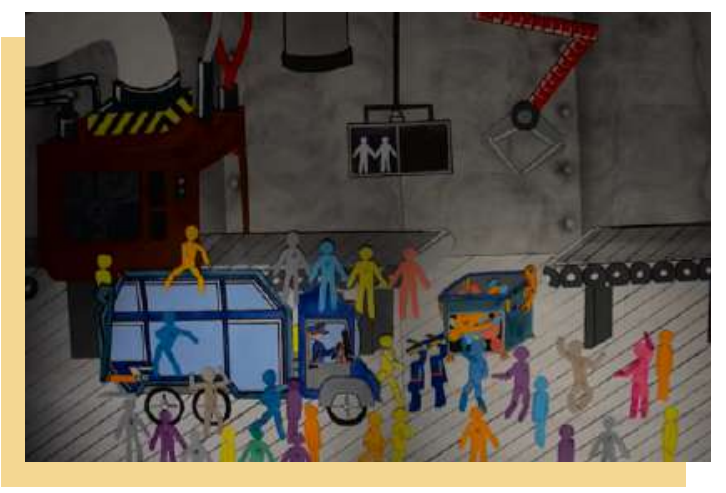

Tomado de https://www.youtube.com/ watch? $v=\mathrm{Jkj} 4$ UZEf2MA\&t $=218 \mathrm{~s}$

A través de la construcción de narrativas se pudo comprender la forma en la cual los estudiantes de Ciney Televisión subjetivizan y conceptualizan sobre el género, en donde se observan rasgos concernientes a la configuración histórica tradicional, así como su autoconcepto a lo que género refiere. En este sentido, se puede observar la naturalización de aspectos y roles que reflejan la hegemonía de la sociedad patriarcal, que de alguna forma acentúa la desigualdad que siempre ha existido entre hombres y mujeres determinadas por cuestiones biológicas y socioculturales. Una de los aspectos diferenciadores entre ellos ha radicado en el significado sobre el cuerpo y su interpretación en los diferentes ámbitos colectivos. Ante esto se plantea en las narrativas la posibilidad de resignificar vivencias corporales que lleven a la deconstrucción de la identidad y así resignificar lo que el género refiere.

Cada uno de estos cortometrajes son el reflejo de una existente dicotomía entre las imposiciones y exigencias de un contexto social y por otro lado la libertad de una construcción propia del ser. La subversión del género a través del cuerpo es uno de los focos de estas narrativas enmarcados en un cuerpo que no responde a las exigencias sociales. El autoconcepto es una implicación que va más allá de una distinción física y biológica, problemática que vivencia el personaje de No Binario a partir de sus ejercicios introspectivos y cuestionamientos acerca de su entorno.

Esto implica que dicha dicotomía entre cuerpo e identidad presenta una fragmentación referente a las imposiciones del sistema heteronormativo, ya que permite suscitar que la configuración de cada ser humano no solo se ve regulada por estándares y normalizaciones colectivas, sino por la facultad que el sujeto posee para transformar los discursos impuestos en su existencia. De esta manera se considera que la construcción del concepto sobre género es una cuestión que se va más allá de una manifestación corpórea.

Cada uno de estos cortometrajes y su contenido poseen un valor simbólico que a través de las técnicas y recursos que contribuyeron en su diseño, permitieron visualizar las construcciones e imaginarios establecidos consuetudinariamente. Elementos como el uso del color, planos cinematográficos, técnica de diseño y animación, frases y enunciaciones, personajes con determinados rasgos y atributos físicos, la posición de los actores, etc., se conjugan sistemáticamente para dar a luz una secuencia lógica de hechos y expresiones que dan cuenta de nuestra visión del mundo a través del lenguaje cinematográfico.

Hoy en día, cada una de las actividades diarias de los individuos, experiencias, 
vivencias y creencias, se encuentran inmersas en un contexto tecnomediado en el que la influencia de las imágenes y los medios de comunicación reconfiguran el orden social, haciendo que la expresión sobre nuestras vidas le sean otorgadas un grado de significación y trascienda en los colectivos. A través de las imágenes y los recursos semióticos audiovisuales empleados en los cortometrajes, se proponen mecanismos de transformación social en los que un grupo en particular de una comunidad social por un lado expone cada una las convenciones y rigidez de un sistema heteronormativo, pero por el otro es un proceso de sublevación y emergencia de nuevos sentires sobre la realidad.

Youtube como canal de difusión y trasmisión de las historias de los cortometrajes elegido por los estudiantes, revela la intervención de algunos usuarios a través de sus comentarios o likes con respecto a las producciones, teniendo en cuenta aspectos de diseño y tipo de mensaje.

\section{Referencias bibliográficas}

Butler, J. (2001). El género en disputa. México: Paidós.

Butler, J (2006). Deshacer el género. Barcelona. Paidós

De Beauvoir, S. (1962). El segundo sexo. Siglo Veinte. Buenos Aires.

Foucault, M. (1990). Vigilar y castigar: nacimiento de la prisión. Siglo XXI Editores Argentina. 2002 (Traducción de Aurelio Garzón del Camino)

Heller, E. (2004). Psicología del color. Como actúan los colores sobre los sentimientos y la razón. Barcelona: Gustavo Gili.

Kress, G. Van Leeuwen, T. (2001). Multimodal Discourse. The modes and media of contemporary communication. pp 1-23. London: Arnold.

Lamas, M. (1986). La antropología feminista y la categoría" género". Tomado de: El Género. La Construcción cultural de la diferencia sexual. Pág 97-125

Lamas, M. (2002). Cuerpo: diferencia sexual y género. México: Taurus.

Lasierra, I. Bonaut, J. (2016): "Estrategias narrativas y estéticas en el paso del cortometraje al largometraje: análisis del caso de Paula Ortiz", en Miguel Hernández Communication Journal, $n^{\circ} 7$, páginas 419 a 441 . Universidad Miguel Hernández, UMH (Elche-Alicante).

Pérez Lo Presti, A y Reinoza D, M. (2011) El educador y la familia disfuncional. En: Revista Educere. Ediciones Universidad de los Andes. Facultad de Humanidades y Educación. Año 15 N²2. Septiembrediciembre de 2011. Mérida, Venezuela.

Reguillo, R (2000). Emergencias de culturas juveniles. Estrategias del desencanto. Grupo Editorial Norma. 1a Edición. Argentina. 182 pp.

Wong, W. (1992). Fundamentos del diseño bi y tridimensional. Gustavo Gili.

\section{Para citar este artículo:}

Miranda, L. (2019). Institucionalización del ser en los cortometrajes La Fábrica y No Binario. Revista Luciérnaga Comunicación. Vol. 11, N22. Pp. 84 - 94. Doi: https://doi. org/10.33571/revistaluciernaga.v11n22a3

OJS. https://revistas.elpoli.edu.co/index.php/luc/issue/archive 